\title{
Fuzzy Integral Multiple Criteria Decision Making Method Based on Fuzzy Preference Relation on Alternatives
}

\author{
Qiaojiao ZHAO \\ School of Mathematics and Computing Science, Guilin University of Electronic Technology, Guilin \\ 541004, China \\ E-mail: 18811322986@163.com \\ Ling ZENG \\ School of Mathematics and Computing Science, Guilin University of Electronic Technology, Guilin \\ 541004, China \\ E-mail:lzeng@guet.edu.cn \\ Jinjin LIU \\ School of Mathematics and Computing Science, Guilin University of Electronic Technology, Guilin \\ 541004, China \\ E-mail: 15577301064@163.com
}

\begin{abstract}
A new method is proposed to solve the multiple criteria decision making with interacting criteria, where the preference information on alternatives in a fuzzy relation given by the decision maker. On the basis of the decision maker's preference information, two types of models — the least squares model, the linear programming model — are constructed to determine the capacities and then to select the most desirable alternative. Finally, a numerical example is used to illustrate the validity and practicality of the proposed method.
\end{abstract}

Keywords Choquet integral; multiple criteria decision making; fuzzy preference information; interacting criteria

\section{Introduction}

Selecting the most desirable alternative from all of the possible alternatives evaluated on a family of criteria is the problem in multiple criteria decision making $(\mathrm{MCDM})^{[1]}$. The methods that have been designed to solve the MCDM problem consist of two steps: 1) Obtaining the decision information; 2) Ranking alternatives by choosing an appropriate aggregation operator.

In general, it is the most popular for additive model to aggregate the DM' s preference ${ }^{[2]}$. Unfortunately, This model is not able to represent interactions among criteria because it does need an idealistic assumption about preferential independence among criteria. To deal with the interactions among criteria, the Choquet integral ${ }^{[3,4]}$ was introduced to the MCDM. It is

Received August 3, 2015, accepted September 30, 2015

Supported by the National Natural Science Foundation of China (61163041); the Science and Technology Research Program of the Higher Education Institutions of Guangxi, China (2013YB087); Innovation Project of GUET Graduate Education (YJCXS201553) 
an extension of the weighted sum and able to address interaction between criteria in many situations $^{[5]}$. However, In order to use Choquet integral, it is necessary to construct both the value functions and the capacity. Generally, The value functions can be given by the decision maker (DM) easily, the construction of the capacity has an exponential complexity ${ }^{[6-8]}$.

Several particular families of capacities ${ }^{[9-12]}$ have been proposed to reduce the number of parameters of capacity evaluation process. $\lambda$-measures ${ }^{[9]}$ and $k$-additive ${ }^{[10]}$ capacities are the very commonly used of all capacities. In particular, the use of 2-additive capacities is realistic because it's noteworthy that the DM have to express their preference on positive and negative interactions between couples of criteria only.

The approaches to solve MCDM problem with interacting criteria can be divided according to preference information, into two classes. One is that some studies tried to solve MCDM with interacting criteria only from the preference information on criteria like the following: The relative importance and interacting for each pair of criteria ${ }^{[13,14]}$, the partial weak order and the sign of interaction over criteria ${ }^{[15]}$. The other is that the preference information on alternatives, including overall values, preference relation and preference orderings. Mori and Murofushi ${ }^{[16]}$ minimized the average quadratic distance between the overall utilities computed by the Choquet integral and the desired overall values given by the DM, then constructed a quadratic program to identify capacities. Beliakov ${ }^{[17]}$ adopted the least absolute deviation and constructed a linear programming model to identify capacities. Marichal and Roubens ${ }^{[18]}$ proposed the approach, which maximize the minimal difference between the overall utilities of alternatives that have been compared by the DM through the preference relation. Lately, Angilella, Greco and Matarazzo ${ }^{[19]}$ proposed a non-additive robust regression model based on the Choquet integral to identify capacities. This is done on the basis of the preference relation over alternatives and the criteria, the intensity of preference over couples of alternatives and the criteria, and the sign of interaction of couples of criteria as well as the pairwise comparisons on the interaction intensities. Angilella, Greco, et al. ${ }^{[20]}$ presented a heuristic method to construct non-linear optimization model based on the Choquet integral for MCDM with interacting criteria, according to the complete preference orderings in subset of alternatives, some relations of importance between criteria and the sign of interaction between criteria given by the DM.

However, these approaches do not handle the problem where the preference information on alternatives is provided in fuzzy terms. In the paper, we are concerned with the MCDM problem with interacting criteria where the fuzzy preference information on alternatives is provided by the DM. Giving two types of models to solve this problem, i.e., the least squares model and the linear programming model, which seek the capacities that holds the minimum squared deviation and the minimum absolute deviation between the final overall values based on the fuzzy preference relation of alternatives and the final overall values computed by means of the Choquet integral, then to select the most desirable alternative. The main characteristic of the proposed methods is that it has more general for MCDM problem with interacting criteria. The reason is that the other kinds of preference information over alternatives (except for overall values) are always converted into fuzzy preference relation ${ }^{[21,22]}$.

This paper is organized as follows. In Section 2, some basic concepts are introduced. Then, two types of models are constructed in Section 3. Section 4 shows an illustrative example of 
the proposed methods and some conclusions are included in Section 5.

\section{Preliminaries}

Let $D=\left\{d_{1}, d_{2}, \cdots, d_{m}\right\}$ denote a set of $m$ alternatives. $G=\left\{g_{1}, g_{2}, \cdots, g_{n}\right\}$ denote a set of $n$ criteria. Each alternative $d_{i} \in D$ is associated with a profile $g\left(d_{i}\right)=\left(g_{1}\left(d_{i}\right), g_{2}\left(d_{i}\right), \cdots\right.$ $\left.\cdot, g_{n}\left(d_{i}\right)\right) \in R^{n}$ where $g_{j}\left(d_{i}\right)$ represents the utility of $d_{i}$ related to the criterion $g_{j}$, with $g_{j}\left(d_{i}\right) \in R$ $i=1,2, \cdots, m, j=1,2, \cdots, n$.

The fuzzy preference information on alternatives is described by a binary fuzzy relation $P$ in $D$, where $P$ is a mapping $D \times D \rightarrow[0,1]$. $P_{i k}$ denotes the preference degree of alternative $d_{i}$ over $d_{k}$. We suppose that $P$ is reciprocal, by definition ${ }^{[23,24]}$

(i) $P_{i k}+P_{k i}=1, \forall i, k$;

(ii) $P_{i i}=-\left(\right.$ symbol ${ }^{\prime}-^{\prime}$ means that the DM dose not give any preference information on $\left.d_{i}\right), \forall i$.

Definition 1 Let $2^{G}$ be the power set of $G$, the function $\mu: 2^{G} \rightarrow[0,1]$ is called a capacity (fuzzy measure) on $2^{G}$ if the following properties are satisfied ${ }^{[19,20]}$ :

1) $\mu(\emptyset)=0$ and $\mu(G)=1$ (boundary conditions);

2) $\forall S \subseteq T \subseteq G, \mu(S) \leqslant \mu(T)$ (monotonicity condition).

In the context of MCDM analysis, for each subset of criteria $T \subseteq G, \mu(T)$ can be considered as the weight or the importance of $T^{[25]}$. A capacity is said to be additive if $\mu(S \cup T)=$ $\mu(S)+\mu(T)$ where $S \cap T=\emptyset$. In this situation, the $n$ weight (i.e., $\left.\mu\left(\left\{g_{1}\right\}\right), \mu\left(\left\{g_{2}\right\}\right), \cdots, \mu\left(\left\{g_{n}\right\}\right)\right)$ are sufficient to construct the whole capacity. In general, one has to calculate $\left(2^{|G|}-2\right)$ values $\mu(T), \emptyset \subset T \subset G$ when the capacity is non-additive ${ }^{[26]}$.

If the criteria from $G$ are interacting and their importance is represented by a capacity, a suitable aggregation operator is the Choquet integral ${ }^{[25]}$.

Definition 2 Let $d_{k} \in D$ and $\mu$ being a fuzzy measure on $G$, then the Choquet integral is defined as ${ }^{[3,20,26]}$

$$
C_{\mu}\left(d_{k}\right)=\sum_{i=1}^{n}\left[g_{(i)}\left(d_{k}\right)-g_{(i-1)}\left(d_{k}\right)\right] \mu\left(N_{i}\right),
$$

where $(\cdot)$ stands for a permutation of the indices of criteria such that $g_{(1)}\left(d_{k}\right) \leqslant \cdots \leqslant g_{(n)}\left(d_{k}\right)$, $N_{(i)}=\left(g_{(i)}, \cdots, g_{(n)}\right)$ and $g_{(0)}=0$.

Definition 3 The Möbius representation of the fuzzy measure $\mu$ is defined by the function $a: 2^{G} \rightarrow \Re$ such that ${ }^{[10,25]}:$

$$
\mu(S)=\sum_{T \subseteq S} a(T)
$$

$\mu\left(\left\{g_{i}\right\}\right)=a\left(\left\{g_{i}\right\}\right)$, if $S=\left\{g_{i}\right\}$ is a singleton; $\mu\left(\left\{g_{i}, g_{j}\right\}\right)=a\left(\left\{g_{i}\right\}\right)+a\left(\left\{g_{j}\right\}\right)+a\left(\left\{g_{i}, g_{j}\right\}\right)$, if $S=\left(\left\{g_{i}, g_{j}\right\}\right)$ is a couple of criteria.

The Möbius representation $a(S)$ is obtained by $\mu(T)$ in the following way ${ }^{[19,26]}$ :

$$
a(S)=\sum_{T \subseteq S}(-1)^{s-t} \mu(T),
$$

where lower case letters $s$ and $t$ denote the corresponding cardinalities of subsets $S$ and $T$.

Under Möbius representation, properties (1) and (2) can be formulated as ${ }^{[19,26]}$ 
(1a) $a(\emptyset)=0, \quad \sum_{T \subseteq G} a(T)=1$;

(2a) $a\left(\left\{g_{i}\right\}\right)+\sum_{T \subseteq S} a\left(T \cup\left\{g_{i}\right\}\right) \geq 0, \quad \forall g_{i} \in G$ and $\forall S \subseteq G \backslash\left\{g_{i}\right\}$.

The Choquet integral can be rewritten in terms of Möbius representation as ${ }^{[20]}$

$$
C_{\mu}\left(d_{k}\right)=\sum_{T \subseteq G} a(T) \min _{g_{i} \in T} g_{i}\left(d_{k}\right) .
$$

We can see that a capacity $\mu$ on $G$ is defined by the knowledge of $\left(2^{|G|}-2\right)$ coefficients. With the aim of reducing the number of coefficients to be elicited, Grabsich proposed the notion of $k$-additive capacities ${ }^{[10]}$.

Definition 4 Let $k \in\{1,2, \cdots, n\}$. A capacity $\mu$ on $G$ is said to be $k$-additive if its Möbius representation satisfies $a(T)=0$ for all $T \subseteq G$ such that $t>k$ and there exists at least one subset $T$ of cardinal $k$ such that $a(T) \neq 0$.

2-additive capacities has received more and more attention because of its simplicity and realistic in many real decision problems. Hence, we shall consider 2-additive capacities. According to Möbius representation, a value $a\left(\left\{g_{i}\right\}\right)$ for every criterion $g_{i}$ and a value $a\left(\left\{g_{i}, g_{j}\right\}\right)$ for every couple of criteria $\left\{g_{i}, g_{j}\right\}$.

Taking into account the 2 -additive capacities, capacity $\mu$ assigns to set $S \subseteq G$ can be expressed in terms of the Möbius representation as follows ${ }^{[19,26]}$ :

$$
\mu(S)=\sum_{g_{i} \in S} a\left(\left\{g_{i}\right\}\right)+\sum_{\left\{g_{i}, g_{j}\right\} \subseteq S} a\left(\left\{g_{i}, g_{j}\right\}\right), \quad \forall S \subseteq G .
$$

With respect to 2 -additive capacities, properties (1a) and (2a) can be restated as follows ${ }^{[19,26]}$ :

(1b) $a(\emptyset)=0, \quad \sum_{g_{i} \in G} a\left(\left\{g_{i}\right\}\right)+\sum_{\left\{g_{i}, g_{j}\right\} \subseteq G} a\left(\left\{g_{i}, g_{j}\right\}\right)=1$,

(2b) $\left\{\begin{array}{l}a\left(\left\{g_{i}\right\}\right) \geq 0, \quad \forall g_{i} \in G, \\ a\left(\left\{g_{i}\right\}\right)+\sum_{g_{j} \in T} a\left(\left\{g_{i}, g_{j}\right\}\right) \geq 0, \quad \forall g_{i} \in G \text { and } \forall T \subseteq G \backslash\left\{g_{i}\right\}, T \neq \emptyset .\end{array}\right.$

The representation of the Choquet integral is given by

$$
C_{\mu}\left(d_{k}\right)=\sum_{g_{i} \in G} a\left(\left\{g_{i}\right\}\right) g_{i}\left(d_{k}\right)+\sum_{\left\{g_{i}, g_{j}\right\} \subseteq G} a\left(\left\{g_{i}, g_{j}\right\}\right) \min \left\{g_{i}\left(d_{k}\right), g_{j}\left(d_{k}\right)\right\},
$$

and the importance of criteria $g_{i} \in G$, described by the Shapley value can be written as follows $^{[19,26]}$ :

$$
\varphi\left(\left\{g_{i}\right\}\right)=a\left(\left\{g_{i}\right\}\right)+\sum_{g_{j} \in G \backslash\left\{g_{i}\right\}} \frac{a\left(\left\{g_{i}, g_{j}\right\}\right)}{2},
$$

while the interaction index for a couple of criteria $\left\{g_{i}, g_{j}\right\} \subseteq G$ is given by ${ }^{[19,26]}$

$$
\varphi\left(\left\{g_{i}, g_{j}\right\}\right)=a\left(\left\{g_{i}, g_{j}\right\}\right) .
$$

\section{Description of the Methodology}

\subsection{The Preference Information}

The DM can provide some indirect preference information easily, such as the relative importance of criteria and interaction between them, the sign of interaction of criteria and comparisons of intensity of preferences between pairs of criteria ${ }^{[15,19,26]}$. 
Criterion $g_{i}$ is more important than the criterion $g_{j}$ :

$$
\varphi\left(\left\{g_{i}\right\}\right)-\varphi\left(\left\{g_{j}\right\}\right) \geq \delta_{S h} \quad\left(g_{i} \succ g_{j}\right) ;
$$

Criterion $g_{i}$ and $g_{j}$ have the same important:

$$
-\delta_{S h} \leq \varphi\left(\left\{g_{i}\right\}\right)-\varphi\left(\left\{g_{j}\right\}\right) \leq \delta_{S h} \quad\left(g_{i} \sim g_{j}\right) ;
$$

The interaction between criterion $g_{i}$ and $g_{j}$ is stronger than that between criterion $g_{k}$ and $g_{l}$,

$$
\varphi\left(\left\{g_{i}, g_{j}\right\}\right)-\varphi\left(\left\{g_{k}, g_{l}\right\}\right) \geq \delta_{I} \quad\left(\varphi\left(\left\{g_{i}, g_{j}\right\}\right) \succ \varphi\left(\left\{g_{k}, g_{l}\right\}\right)\right)
$$

The interaction between criterion $g_{i}$ and $g_{j}$ is the same as that between criterion $g_{k}$ and $g_{l}$,

$$
-\delta_{I} \leq \varphi\left(\left\{g_{i}, g_{j}\right\}\right)-\varphi\left(\left\{g_{k}, g_{l}\right\}\right) \leq \delta_{I} \quad\left(\varphi\left(\left\{g_{i}, g_{j}\right\}\right) \sim \varphi\left(\left\{g_{k}, g_{l}\right\}\right)\right)
$$

Criterion $g_{i}$ and $g_{j}$ are positive,

$$
\delta_{I} \leq \varphi\left(\left\{g_{i}, g_{j}\right\}\right) \leq 1 \quad\left(\varphi\left(\left\{g_{i}, g_{j}\right\}\right)>0\right)
$$

Criterion $g_{i}$ and $g_{j}$ are negative,

$$
-1 \leq \varphi\left(\left\{g_{i}, g_{j}\right\}\right) \leq-\delta_{I} \quad\left(\varphi\left(\left\{g_{i}, g_{j}\right\}\right)<0\right)
$$

The difference of importance between criterion $g_{i}$ and $g_{j}$ is at least as much as difference of importance between criterion $g_{k}$ and $g_{l}$,

$$
\varphi\left(\left\{g_{i}\right\}\right)-\varphi\left(\left\{g_{j}\right\}\right) \geq \varphi\left(\left\{g_{k}\right\}\right)-\varphi\left(\left\{g_{l}\right\}\right)+\delta_{S h} \quad\left(\varphi\left(\left\{g_{i}\right\}\right)-\varphi\left(\left\{g_{j}\right\}\right)\right) \succ\left(\varphi\left(\left\{g_{k}\right\}\right)-\varphi\left(\left\{g_{l}\right\}\right)\right) ;
$$

The difference of importance between criterion $g_{i}$ and $g_{j}$ is the same as the difference of importance between criterion $g_{k}$ and $g_{l}$,

$-\delta_{S h} \leq\left(\varphi\left(\left\{g_{i}\right\}\right)-\varphi\left(\left\{g_{j}\right\}\right)\right)-\left(\varphi\left(\left\{g_{k}\right\}\right)-\varphi\left(\left\{g_{l}\right\}\right)\right) \leq \delta_{S h} \quad\left(\varphi\left(\left\{g_{i}\right\}\right)-\varphi\left(\left\{g_{j}\right\}\right) \sim\left(\varphi\left(\left\{g_{k}\right\}\right)-\varphi\left(\left\{g_{l}\right\}\right)\right)\right.$ where $\delta_{S h}$ and $\delta_{I}$ are non-negative indifference thresholds defined by the DM.

\subsection{Two Models to MCDM Problem with Interacting Criteria}

In MCDM problem, $C_{\mu}\left(d_{i}\right)(i=1,2, \cdots, m)$ denotes the overall value of alternative $d_{i}$. According to Equation $(6), C_{\mu}\left(d_{i}\right)$ is the function of the $a\left(\left\{g_{i}\right\}\right)(i=1,2, \cdots, n)$ and $a\left(\left\{g_{i}, g_{j}\right\}\right)(i, j=$ $1,2, \cdots, n, i \neq j)$. The fact is that the greater value $C_{\mu}\left(d_{i}\right)$, the better alternative $d_{i}$.

Taking the information uniform into account, we have to convert the overall values of alternatives into fuzzy preference relation. Thus, we define $\tilde{P}_{i k}$ as

$$
\tilde{P}_{i k}=\frac{C_{\mu}\left(d_{i}\right)}{C_{\mu}\left(d_{i}\right)+C_{\mu}\left(d_{k}\right)}, \quad i \neq k,
$$

where the meaning of $\tilde{P}_{i k}$ is similar to that of $P_{i k}$.

The deviation between $P_{i k}$ and $\tilde{P}_{i k}$ is described by

$$
z_{i k}(a)=P_{i k}-\tilde{P}_{i k}=P_{i k}-\frac{C_{\mu}\left(d_{i}\right)}{C_{\mu}\left(d_{i}\right)+C_{\mu}\left(d_{k}\right)}, \quad i \neq k .
$$

The above deviation degree can be transformed into the following form:

$$
h_{i k}(a)=P_{i k}\left(C_{\mu}\left(d_{i}\right)+C_{\mu}\left(d_{k}\right)\right)-C_{\mu}\left(d_{i}\right), \quad i \neq k .
$$


We can minimize the $h_{i k}(a)$ so as to reflect the DM 's preference information with much accuracy. Then, construct the following model.

1) The least squares programming model

$$
\begin{gathered}
\min H(a)=\sum_{i=1}^{m} \sum_{\substack{k=1 \\
k \neq i}}^{m}\left[P_{i k}\left(C_{\mu}\left(d_{i}\right)+C_{\mu}\left(d_{k}\right)\right)-C_{\mu}\left(d_{i}\right)\right]^{2} \\
\left\{\begin{array}{l}
\varphi\left(\left\{g_{i}\right\}\right)-\varphi\left(\left\{g_{j}\right\}\right) \geq \delta_{S h}, \\
-\delta_{S h} \leq \varphi\left(\left\{g_{i}\right\}\right)-\varphi\left(\left\{g_{j}\right\}\right) \leq \delta_{S h}, \\
\delta_{I} \leq \varphi\left(\left\{g_{i}, g_{j}\right\}\right) \leq 1, \\
-1 \leq \varphi\left(\left\{g_{i}, g_{j}\right\}\right) \leq-\delta_{I}, \\
a(\emptyset)=0, \\
\sum_{g_{i} \in G} a\left(\left\{g_{i}\right\}\right)+\sum_{\left\{g_{i}, g_{j}\right\} \subseteq G} a\left(\left\{g_{i}, g_{j}\right\}\right)=1, \\
a\left(\left\{g_{i}\right\}\right) \geq 0, \quad \forall g_{i} \in G, \\
a\left(\left\{g_{i}\right\}\right)+\sum_{g_{j} \in T} a\left(\left\{g_{i}, g_{j}\right\}\right) \geq 0, \quad \forall g_{i} \in G \text { and } \forall T \subseteq G \backslash\left\{g_{i}\right\}, T \neq \emptyset .
\end{array}\right.
\end{gathered}
$$

2) The linear programming model

In order to consist the selection of the alternative and the preference information to the biggest degree, we always hope that the deviation degree can be as small as possible. Therefore, we construct the linear programming model.

$$
\min Z_{i k}(a)=\left|P_{i k}\left(C_{\mu}\left(d_{i}\right)+C_{\mu}\left(d_{k}\right)\right)-C_{\mu}\left(d_{i}\right)\right| i, k=1,2, \cdots, m, i \neq k .
$$

Assume that the expected value of objective function is 0 , therefore, the model can be transformed into the following:

$$
\begin{aligned}
& \min H=\sum_{i=1}^{m} \sum_{\substack{k=1 \\
k \neq i}}^{m}\left(S_{i k}^{+}+S_{i k}^{-}\right) \\
& \left\{\begin{array}{l}
P_{i k}\left(C_{\mu}\left(d_{i}\right)+C_{\mu}\left(d_{k}\right)\right)-C_{\mu}\left(d_{i}\right)-S_{i k}^{+}+S_{i k}^{-}=0, \\
S_{i k}^{+} \geq 0, S_{i k}^{-} \geq 0, i, k=1,2, \cdots, m, i \neq k, \\
\varphi\left(\left\{g_{i}\right\}\right)-\varphi\left(\left\{g_{j}\right\}\right) \geq \delta_{S h}, \\
-\delta_{S h} \leq \varphi\left(\left\{g_{i}\right\}\right)-\varphi\left(\left\{g_{j}\right\}\right) \leq \delta_{S h}, \\
\delta_{I} \leq \varphi\left(\left\{g_{i}, g_{j}\right\}\right) \leq 1, \\
-1 \leq \varphi\left(\left\{g_{i}, g_{j}\right\}\right) \leq-\delta_{I}, \\
a(\emptyset)=0, \quad \sum_{\left\{g_{i}, g_{j}\right\} \subseteq G} a\left(\left\{g_{i}, g_{j}\right\}\right)=1, \\
\sum_{g_{i} \in G} a\left(\left\{g_{i}\right\}\right)+\quad \sum_{i} \in G, \\
a\left(\left\{g_{i}\right\}\right) \geq 0, \quad \forall g_{i} \in G, \quad \forall g_{i} \in G \text { and } \forall T \subseteq G \backslash\left\{g_{i}\right\}, T \neq \emptyset \\
a\left(\left\{g_{i}\right\}\right)+\sum_{g_{j} \in T} a\left(\left\{g_{i}, g_{j}\right\}\right) \geq 0,
\end{array}\right.
\end{aligned}
$$


where $S_{i k}^{+}$denotes the value that the objective function $z_{i k}$ is greater than its expected value, $S_{i k}^{-}$denotes the value that the objective function $z_{i k}$ is smaller than its expected value.

The two models can be solved by using the quadratic programming method and linear programming method. We can have the Möbius representation which respect the constraints relative to importance and interaction between criteria given by the DM. Then, we can obtain the capacities as well as the Shapley value of criteria, at last we can get the alternative ranking by Choquet integral.

\section{An Illustrative Example}

The whole methodology will be illustrated by a practical example. We suppose that the DM has to rank the cars of Table 1 according to his/her preference. The cars are evaluated on four criteria: price in Euro (P), acceleration $0-100 \mathrm{~km} / \mathrm{h}$ in seconds $(\mathrm{A})$, maximum speed in $\mathrm{km} / \mathrm{h}(\mathrm{MS})$, consumption in $\mathrm{km} / \mathrm{l}$ (C) (adapted from [20]).

The DM's fuzzy preference relation on seven cars are given in Table 2. Making the evaluations on all criteria is expressed on the same scale. As shown in [24] (Table 3). And explicit preference information with respect to the important and the interaction of the considered criteria are given as follows:

$$
\begin{aligned}
& P \succ A, \quad A \succ C, \\
& \varphi(\{P, A\})>0, \quad \varphi(\{P, M S\})>0, \quad \varphi(\{A, C\})>0, \quad \varphi(\{M S, C\})>0, \\
& \varphi(\{P, C\})<0, \quad \varphi(\{A, M S\})<0 .
\end{aligned}
$$

The above constraints can be translated as:

$$
\begin{aligned}
& \varphi(\{P\})-\varphi(\{A\}) \geq \delta_{S h}, \quad \varphi(\{A\})-\varphi(\{C\}) \geq \delta_{S h}, \\
& \delta_{I} \leq \varphi(\{P, A\}) \leq 1, \quad \delta_{I} \leq \varphi(\{P, M S\}) \leq 1, \quad \delta_{I} \leq \varphi(\{A, C\}) \leq 1, \\
& \delta_{I} \leq \varphi(\{M S, C\}) \leq 1, \quad-1 \leq \varphi(\{P, C\}) \leq-\delta_{I}, \quad-1 \leq \varphi(\{A, M S\}) \leq-\delta_{I},
\end{aligned}
$$

where the indifference thresholds $\delta_{I}$ and $\delta_{S h}$ are supposed to have been set to 0.05 and 0.01 by the $\mathrm{DM}^{[25]}$.

Table 1 The partial evaluations of seven cars

\begin{tabular}{ccclc}
\hline Cars & Euro & $\begin{array}{c}\text { Acceleration } \\
0 / 100(\mathrm{~km} / \mathrm{h})\end{array}$ & $\begin{array}{c}\text { Max speed } \\
(\mathrm{km} / \mathrm{h})\end{array}$ & $\begin{array}{c}\text { Consumption } \\
(\mathrm{km} / \mathrm{l})\end{array}$ \\
\hline AudiA3 1.6 Attraction & 19,000 & 11 & 188 & 13 \\
BMW 316i & 23,000 & 13 & 195 & 11 \\
Daewoo Nexia 1.5i GL 5p & 14,000 & 12 & 165 & 14 \\
Ford Escort Cabrio 1.6 16v Luxury & 18,000 & 13 & 173 & 13 \\
Rover 111 Kensington SE 3p & 8,600 & 14 & 153 & 15 \\
Seat Ibiza 1.4 5p Slalom & 11,000 & 15 & 157 & 14 \\
Volks Wagen Polo 1.6 3P Sportline & 13,000 & 12 & 172 & \\
\hline
\end{tabular}


Table 2 Fuzzy preference relation on seven cars by the DM

\begin{tabular}{cccccccc}
\hline & Audi A3 & BWM 326i & Daewoo N & Ford Escort & Rover 111 & Seat Ibiza & Volks WP \\
\hline Audi A3 & - & $0.64^{a}$ & 0.72 & 0.56 & 0.65 & 0.58 & 0.54 \\
BMW 316i & 0.36 & - & 0.55 & 0.63 & 0.57 & 0.60 & 0.45 \\
Daewoo N & 0.28 & 0.45 & - & 0.55 & 0.48 & 0.57 & 0.45 \\
Ford Escort & 0.44 & 0.37 & 0.45 & - & 0.45 & 0.56 & 0.35 \\
Rover 111 & 0.35 & 0.43 & 0.52 & 0.55 & - & 0.57 & 0.31 \\
Seat Ibiza & 0.42 & 0.40 & 0.43 & 0.44 & 0.43 & - & 0.34 \\
Volks WP & 0.46 & 0.55 & 0.55 & 0.65 & 0.69 & 0.66 & - \\
\hline
\end{tabular}

${ }^{a} 0.64$ denotes the preference degree of alternative Audi A3 over BWM 326i (i.e., $P_{12}=0.64$ ).

Table 3 Criteria values of seven cars expressed on the same scale

\begin{tabular}{ccccc}
\hline Cars & Euro & $\begin{array}{c}\text { Acceleration } \\
0 / 100(\mathrm{~km} / \mathrm{h})\end{array}$ & $\begin{array}{c}\text { Max speed } \\
(\mathrm{km} / \mathrm{h})\end{array}$ & $\begin{array}{c}\text { Consumption } \\
(\mathrm{km} / \mathrm{l})\end{array}$ \\
\hline AudiA3 1.6 Attraction & 0.2778 & 1.0000 & 0.8333 & 0.4000 \\
BMW 316i & 0.0000 & 0.5000 & 1.0000 & 0.0000 \\
Daewoo Nexia 1.5i GL 5p & 0.6250 & 0.7500 & 0.2857 & 0.6000 \\
Ford Escort Cabrio 1.6 16v Luxury & 0.3472 & 0.5000 & 0.4762 & 0.4000 \\
Rover 111 Kensington SE 3p & 1.0000 & 0.2500 & 0.0000 & 1.0000 \\
Seat Ibiza 1.4 5p Slalom & 0.8333 & 0.0000 & 0.0952 & 0.8000 \\
Volks Wagen Polo 1.6 3P Sportline & 0.6944 & 0.7500 & 0.4524 & 0.6000 \\
\hline
\end{tabular}

We can construct the least squares programming model. Solving this programming by the mathematical software lingo. It is possible to obtain their Möbius representations and the fuzzy measures as well as the Shapley value. The results are show in Tables 4-6. Finally, we have the overall values of seven cars and get the ranking of seven cars, as shown in Table 7 .

Table 4 The Möbius representation $m$

\begin{tabular}{cccc}
\hline Criteria & Value & Criteria & Value \\
\hline$\{\mathrm{P}\}$ & 0.3020 & $\{\mathrm{P}, \mathrm{MS}\}$ & 0.0719 \\
$\{\mathrm{~A}\}$ & 0.0600 & $\{\mathrm{P}, \mathrm{C}\}$ & -0.0500 \\
$\{\mathrm{MS}\}$ & 0.4660 & $\{\mathrm{~A}, \mathrm{MS}\}$ & -0.0500 \\
$\{\mathrm{C}\}$ & 0.0500 & $\{\mathrm{~A}, \mathrm{C}\}$ & 0.0500 \\
$\{\mathrm{P}, \mathrm{A}\}$ & 0.0500 & $\{\mathrm{MS}, \mathrm{C}\}$ & 0.0500 \\
\hline
\end{tabular}


Table 5 Fuzzy measures $\mu\left(\left\{g_{i}, g_{j}\right\}\right)$ of couples of criteria

\begin{tabular}{cc}
\hline Couples of criteria & Value \\
\hline$\{\mathrm{P}, \mathrm{A}\}$ & 0.4120 \\
$\{\mathrm{P}, \mathrm{MS}\}$ & 0.8400 \\
$\{\mathrm{P}, \mathrm{C}\}$ & 0.3019 \\
$\{\mathrm{~A}, \mathrm{MS}\}$ & 0.4760 \\
$\{\mathrm{~A}, \mathrm{C}\}$ & 0.1600 \\
$\{\mathrm{MS}, \mathrm{C}\}$ & 0.5660 \\
\hline
\end{tabular}

Table 6 Fuzzy measures $\mu\left(\left\{g_{i}\right\}\right)$ and Shapley value $\varphi\left(\left\{g_{i}\right\}\right)$ of criteria

\begin{tabular}{ccc}
\hline Criteria & Value $\mu\left(\left\{g_{i}\right\}\right)$ & Value $\varphi\left(\left\{g_{i}\right\}\right)$ \\
\hline$\{\mathrm{P}\}$ & 0.3020 & 0.3379 \\
$\{\mathrm{~A}\}$ & 0.0600 & 0.0850 \\
$\{\mathrm{MS}\}$ & 0.4660 & 0.5020 \\
$\{\mathrm{C}\}$ & 0.0500 & 0.0751 \\
\hline
\end{tabular}

Table 7 The overall values and the ranking of seven cars by using Choquet integral

\begin{tabular}{cccccccc}
\hline & Audi A3 & BWM 326i & Daewoo N & Ford Escort & Rover 111 & Seat Ibiza & Volks WP \\
\hline Choquet integral & 0.5705 & 0.4710 & 0.4487 & 0.4179 & 0.3420 & 0.3076 & 0.5628 \\
Ranking & 1 & 3 & 4 & 5 & 6 & 7 & 2 \\
\hline
\end{tabular}

Table 8 The Möbius representation $m$

\begin{tabular}{cccc}
\hline Criteria & Value & Criteria & Value \\
\hline$\{\mathrm{P}\}$ & 0.3083 & $\{\mathrm{P}, \mathrm{MS}\}$ & 0.0749 \\
$\{\mathrm{~A}\}$ & 0.0600 & $\{\mathrm{P}, \mathrm{C}\}$ & -0.0500 \\
$\{\mathrm{MS}\}$ & 0.4567 & $\{\mathrm{~A}, \mathrm{MS}\}$ & -0.0500 \\
$\{\mathrm{C}\}$ & 0.0500 & $\{\mathrm{~A}, \mathrm{C}\}$ & 0.0500 \\
$\{\mathrm{P}, \mathrm{A}\}$ & 0.0500 & $\{\mathrm{MS}, \mathrm{C}\}$ & 0.0500 \\
\hline
\end{tabular}

According to the linear programming model, we have the optional solution, as shown in Table 8. The fuzzy measures of couples of criteria and the Shapley value are listed in Tables 9-10, the overall values and the ranking of seven cars are in Table 11.

In Table 6 and Table 10, we observe that the Shapley value of price is greater than that of the criterion acceleration, which is greater than that of criterion consumption. It showed that the preference of the DM are presented by the model. At the same time, From Table 7 and Table 11, we can see the ranking obtained by the least squares programming is the same as that obtained by the method of linear programming. 
Table 9 Fuzzy measures $\mu\left(\left\{g_{i}, g_{j}\right\}\right)$ of couples of criteria

\begin{tabular}{cc}
\hline Couples of criteria & Value \\
\hline$\{\mathrm{P}, \mathrm{A}\}$ & 0.4183 \\
$\{\mathrm{P}, \mathrm{MS}\}$ & 0.8400 \\
$\{\mathrm{P}, \mathrm{C}\}$ & 0.3083 \\
$\{\mathrm{~A}, \mathrm{MS}\}$ & 0.4667 \\
$\{\mathrm{~A}, \mathrm{C}\}$ & 0.1600 \\
$\{\mathrm{MS}, \mathrm{C}\}$ & 0.5567 \\
\hline
\end{tabular}

Table 10 Fuzzy measures $\mu\left(\left\{g_{i}\right\}\right)$ and Shapley value $\varphi\left(\left\{g_{i}\right\}\right)$ of criteria

\begin{tabular}{ccc}
\hline Criteria & Value $\mu\left(\left\{g_{i}\right\}\right)$ & Value $\varphi\left(\left\{g_{i}\right\}\right)$ \\
\hline$\{\mathrm{P}\}$ & 0.3083 & 0.3458 \\
$\{\mathrm{~A}\}$ & 0.0600 & 0.0850 \\
$\{\mathrm{MS}\}$ & 0.4567 & 0.4942 \\
$\{\mathrm{C}\}$ & 0.0500 & 0.0750 \\
\hline
\end{tabular}

Table 11 The overall values and the ranking of seven cars by using Choquet integral

\begin{tabular}{cccccccc}
\hline & Audi A3 & BWM 326i & Daewoo N & Ford Escort & Rover 111 & Seat Ibiza & Volks WP \\
\hline Choquet integral & 0.5654 & 0.4617 & 0.4508 & 0.4167 & 0.3483 & 0.3123 & 0.5643 \\
Ranking & 1 & 3 & 4 & 5 & 6 & 7 & 2 \\
\hline
\end{tabular}

\section{Conclusions}

In this paper, We gave the least squares programming model and the linear programming model to solve MCDM problem with interacting criteria. Compared with the methods based on the preference information. The proposed approach that considers the fuzzy relation on alternatives given by the DM is relatively reasonable. The ranking of the alternatives combined the fuzzy preference information with the partial evaluations of the alternatives, and reflected the preference information of DM to the maximum extent.

\section{References}

[1] Figueira J, Greco S, Ehrgott M. Multiple criteria decision analysis: State of the art surveys. Springer Science and Business Media, 2005.

[2] Greco S, Mousseau V, Slowiński R. Robust ordinal regression for value functions handling interacting criteria. European Journal of Operational Research, 2014, 239(3): 711-730.

[3] Choquet G. Theory of capacities//Annales de l'institut Fourier. Institut Fourier, 1954, 5: 131-295.

[4] Grabisch M. The application of fuzzy integrals in multicriteria decision making. European Journal of Operational Research, 1996, 89(3): 445-456.

[5] Murofushi T, Sugeno M. An interpretation of fuzzy measures and the Choquet integral as an integral with respect to a fuzzy measure. Fuzzy Sets and Systems, 1989, 29(2): 201-227.

[6] Grabisch M, Labreuche C. A decade of application of the Choquet and Sugeno integrals in multi-criteria decision aid. Annals of Operations Research, 2010, 175(1): 247-286. 
[7] Grabisch M. Fuzzy integral in multicriteria decision making. Fuzzy sets and Systems, 1995, 69(3): 279-298.

[8] Grabisch M. The application of fuzzy integrals in multicriteria decision making. European Journal of Operational Research, 1996, 89(3): 445-456.

[9] Sugeno M. Construction of fuzzy measures and evaluation of similarity patterns by fuzzy integral. Transactions of the SICE, 1973, 9: 361-368.

[10] Grabisch M. K-order additive discrete fuzzy measures and their representation. Fuzzy Sets and Systems, 1997, 92(2): 167-189.

[11] Marichal J L. Tolerant or intolerant character of interacting criteria in aggregation by the Choquet integral. European Journal of Operational Research, 2004, 155(3): 771-791.

[12] Marichal J L. $k$-intolerant capacities and Choquet integrals. European Journal of Operational Research, 2007, 177(3): 1453-1468.

[13] Takahagi E. A fuzzy measure identification method by diamond pairwise comparisons and $\phi_{s}$ transformation. Fuzzy Optimization and Decision Making, 2008, 7(3): 219-232.

[14] Wu J Z, Zhang Q. 2-order additive fuzzy measure identification method based on diamond pairwise comparison and maximum entropy principle. Fuzzy Optimization and Decision Making, 2010, 9(4): 435453.

[15] Wu J Z, Zhang Q, Du Q, et al. Compromise principle based methods of identifying capacities in the framework of multicriteria decision analysis. Fuzzy Sets and Systems, 2014, 246: 91-106.

[16] Mori T, Murofushi T. An analysis of evaluation model using fuzzy measure and the Choquet integral. 5th Fuzzy System Symposium, 1989: 207-212.

[17] Beliakov G. Construction of aggregation functions from data using linear programming. Fuzzy Sets and Systems, 2009, 160(1): 65-75.

[18] Marichal J L, Roubens M. Determination of weights of interacting criteria from a reference set. European Journal of Operational Research, 2000, 124(3): 641-650.

[19] Angilella S, Greco S, Matarazzo B. Non-additive robust ordinal regression: A multiple criteria decision model based on the Choquet integral. European Journal of Operational Research, 2010, 201(1): 277-288.

[20] Angilella S, Greco S, Lamantia F, et al. Assessing non-additive utility for multicriteria decision aid. European Journal of Operational Research, 2004, 158(3): 734-744.

[21] Foerster J F. Mode choice decision process models: A comparison of compensatory and non-compensatory structures. Transportation Research Part A: General, 1979, 13(1): 17-28.

[22] Zhang Q, Wang Y, Yang Y. Fuzzy multiple attribute decision making with eight types of preference information on alternatives. 2007 IEEE Symposium on Computational Intelligence in Multi-Criteria DecisionMaking, 2007.

[23] Chiclana F, Herrera F, Herrera-Viedma E. Integrating three representation models in fuzzy multipurpose decision making based on fuzzy preference relations. Fuzzy Sets and Systems, 1998, 97(1): 33-48.

[24] Fan Z P, Ma J, Zhang Q. An approach to multiple attribute decision making based on fuzzy preference information on alternatives. Fuzzy Sets and Systems, 2002, 131(1): 101-106.

[25] Grabisch M, Kojadinovic I, Meyer P. A review of methods for capacity identification in Choquet integral based multi-attribute utility theory: Applications of the Kappalab R package. European Journal of Operational Research, 2008, 186(2): 766-785.

[26] Angilella S, Corrente S, Greco S. Stochastic multiobjective acceptability analysis for the Choquet integral preference model and the scale construction problem. European Journal of Operational Research, 2015, 240(1): $172-182$. 